\section{Clinical features and surgical management of retinal detachment secondary to round retinal holes}

\begin{abstract}
Aims The majority of rhegmatogenous retinal detachments result from pathological posterior vitreous detachment (PVD) and secondary horseshoe or giant retinal tears. Retinal detachment without PVD is usually associated with either retinal dialysis or round retinal holes. This study characterises the features, surgical outcome, and incidence of bilateral involvement of detachment associated with round retinal holes Methods In all, 110 retinal detachments from 96 consecutive patients with retinal detachment secondary to round retinal holes were studied. Analysis of patient age, sex, refraction, preoperative visual acuity, presented symptoms, position and extent of detachment, number and distribution of holes present, posterior hyaloid membrane status, surgical management, outcome of surgery, and postoperative visual acuity were studied. Results The mean age for patients was 34 years with a marked female preponderance $(64 \%)$ and myopia (83\%). The posterior hyaloid membrane remained attached in 95 eyes $(86 \%)$. In all, $45 \%$ patients had bilateral pathology, of which $33 \%$ had 'mirror image' distribution. Detachments were predominantly shallow (93\%) and slow in progression (17\%). A total of 100 detachments were repaired with cryotherapy and scleral buckling, eight with cryotherapy alone, and one with laser retinopexy. In all, 99\% detachments were successfully reattached with a single procedure. The mean follow-up period was 2 years. There were no instances of redetachment.

Conclusions Round hole detachments are slowly evolving detachments with attached vitreous gel in young, predominantly female
\end{abstract}

T Ung, MB Comer, AJS Ang, R Sheard, C Lee, AV Poulson, DK Newman, JD Scott, AJ Richards and MP Snead

myopes. Examination of the fellow eye should be mandatory as there is a high incidence of bilateral pathology. Scleral buckling procedures remained highly effective in this selected group of patients.

Eye (2005) 19, 665-669. doi:10.1038/sj.eye.6701618

Published online 3 September 2004

Keywords: posterior hyaloid membrane; retinal detachment; retinal hole; vitreous

\section{Introduction}

The majority of rhegmatogenous retinal detachments result from pathological posterior vitreous detachments (PVD) that lead to secondary horseshoe or giant retinal tears. Retinal detachment without PVD is more usually associated with either retinal dialysis or round retinal holes (Table 1 ).

The natural history of round hole within the lattice is well established, ${ }^{1}$ together with the notion that such holes are an infrequent cause of retinal detachment. ${ }^{1,2,3}$ However, round holes account for a significant minority of cases presenting with retinal detachment, ranging from 2 to $21 \%$ in some reported series. ${ }^{4-6}$ In 1976, Tillery and Lucier ${ }^{4}$ described the characteristics of retinal detachments arising from round hole situated within lattice retinopathy in 60 patients. They found that round-hole detachments were found predominantly in young myopic patients, with no predilection to either sexes. These detachments were commonly situated in the inferior quadrants, which obtained high successful surgical repairs with scleral buckling procedures. However, the state of the vitreous in these patients was not studied. These findings were confirmed in a Japanese study of
Vitreoretinal Service Addenbrooke's NHS Trust Cambridge, UK

Correspondence: MP Snead Vitreoretinal Service BOX 41 Addenbrooke's NHS Trust Hills Road Cambridge CB2 2QQ, UK Tel: + 441223216701 Fax: + 441223217968 E-mail: mps34@cam.ac.uk

Received: 9 March 2004 Accepted: 29 March 2004 Published online: 3 September 2004 
Table 1 The 'Cambridge Guide' to the features associated with the seven most common varieties of primary retinal break in rhegmatogenous retinal detachment

\begin{tabular}{|c|c|c|c|c|c|c|c|}
\hline Break type & $\begin{array}{l}\text { PHM } \\
\text { status }\end{array}$ & $\begin{array}{l}\text { Vitreous } \\
\text { Architecture }\end{array}$ & $\operatorname{Sex}$ & $\begin{array}{l}\text { Typical age } \\
\text { group (years) }\end{array}$ & $\begin{array}{l}\text { Refractive } \\
\text { error }\end{array}$ & $\begin{array}{c}\text { Fellow-eye involvement/ } \\
\text { pathology }\end{array}$ & Reference \\
\hline Atraumatic dialysis & On & Normal & $\mathrm{M}>\mathrm{F}$ & $8-20$ & $\begin{array}{l}\text { Emmetropia/ } \\
\text { hypermetropia }\end{array}$ & $5-15 \%$ & 11 \\
\hline Giant retinal tear & Off & $\begin{array}{l}\text { Check for } \\
\text { anomaly }\end{array}$ & $\mathrm{M}=\mathrm{F}$ & $5-50$ & $\begin{array}{l}\text { Moderate/ } \\
\text { high myopia }\end{array}$ & Variable up to $80 \%$ & 12,13 \\
\hline Horseshoe tear & Off & $\begin{array}{l}\text { Usually } \\
\text { syneretic }\end{array}$ & $\mathrm{M}=\mathrm{F}$ & $45-65$ & $\begin{array}{l}\text { Moderate/ } \\
\text { high myopia }\end{array}$ & $10 \%$ & 14 \\
\hline Round retinal hole & On & $\begin{array}{l}\text { Usually } \\
\text { normal }\end{array}$ & $\mathrm{F}>\mathrm{M}$ & $20-40$ & Moderate myopia & $45 \%$ & This study \\
\hline Macular hole & Off & Syneretic & $\mathrm{M}=\mathrm{F}$ & $45-65$ & High myopia & Rare & 15,16 \\
\hline Reticular schisis & On & Normal & $\mathrm{M}>\mathrm{F}$ & $70+$ & Hypermetropia & $80 \%$ & 17,18 \\
\hline X-linked retinoschisis & On & $\begin{array}{l}\text { Normal, } \\
\text { may have } \\
\text { haemorrhage }\end{array}$ & M & $10-20$ & Emmetropia & $100 \%$ & 19 \\
\hline
\end{tabular}

$\overline{\mathrm{PHM}}=$ posterior hyaloid membrane; Macular hole refers to macular hole associated with retinal detachment as distinct from isolated 'idiopathic' macular hole.

40 patients, 7 years later. ${ }^{6}$ Murakami-Nagasako and $\mathrm{Ohba}^{6}$ looked at the vitreous states in their patients and found that $34 \%$ of them had a posterior viterous detachment at the time of presentation.

We have observed that round holes responsible for retinal detachment may also occur without associated lattice retinopathy. Our study investigates the characteristics of a consecutive series of detachments due to lattice round hole or nonlattice round hole.

\section{Method}

A consecutive series of patients presenting to Addenbrooke's Hospital from 1994 to 2002 with retinal detachments attributable to round hole were retrospectively analysed. The patients were identified using the vitreoretinal database which contains diagnostic details of all patients operated by the unit, and their corresponding medical notes were examined.

The detachments were classified into those due to solitary or multiple round holes. Further sub-classification was made into those that were lattice round hole or nonlattice round holes. Lattice round holes were defined by round hole within lattice retinopathy. Nonlattice round holes were defined by round hole that were situated outside the lattice retinopathy or without any existing lattice degeneration. Detachments that featured round operculated tears (ie horseshoe tears that appear 'round' due to complete avulsion of the flap operculum) were excluded.

The following characteristics were also documented for each patient: age, sex, refraction, symptoms at presentation, visual acuity (VA) at presentation, presence or absence of a PVD, the nature, site and extent of the detachment, the number and distribution of the round holes, fellow eye pathology, surgical procedure performed, anatomical outcome, and the final postoperative visual acuity.

Posterior vitreous detachment was defined as a clearly visible continuous sheet of posterior hyaloid membrane with or without an associated Weiss ring (as per departmental protocol).

Descriptive analysis was performed to summarise the characteristics of the different subgroups and the Fisher's exact test was used to detect any significant differences between the groups. A $P$-value of $<0.05$ was taken to be statistically significant.

\section{Results}

In all, 110 round-hole retinal detachments from 96 patients were identified and evaluated. This accounted for $10 \%$ of the primary retinal detachment presenting to our tertiary referral vitreoretinal service. In 29 of the 110 (26.4\%) detachments solitary round holes were found on examination; one was associated with white-withoutpressure retinopathy and none were lattice round holes. In all, 81 of the $110(73.6 \%)$ detachments had multiple round holes of which $26(23.6 \%)$ were lattice round holes and $55(50 \%)$ were nonlattice round hole.

Patient demographics are summarised in Table 2. In summary, they were predominantly young (mean 34 years, range 7-74 years) (Figure 1) with a female preponderance $(64 \%)$ and associated with moderate myopia. Of 83 patients with preoperative refraction recorded, 82 were myopic (mean -5.0 dioptres, range -0.75 to -12.0 dioptres). One patient was emmetropic (Figure 2). 
Table 2 Comparison among subgroups of round-hole detachments

\begin{tabular}{|c|c|c|c|}
\hline & $\begin{array}{l}\text { Solitary } \\
\text { RH (\%) }\end{array}$ & $\begin{array}{c}\text { Multiple } \\
\text { lattice } \\
\text { RH }(\%)\end{array}$ & $\begin{array}{c}\text { Multiple } \\
\text { nonlattice } \\
\text { RH }(\%)\end{array}$ \\
\hline Age $<30$ years & 50 & 39 & 60 \\
\hline Female & 61 & 60 & 65 \\
\hline Refraction $-4.0--7.0$ & 74 & 60 & 55 \\
\hline Initial VA $6 / 12$ or better & 61 & 87 & 81 \\
\hline PHM on & 93 & 88 & 91 \\
\hline Fellow-eye pathology ${ }^{a}$ & 48 & 96 & 79 \\
\hline Shallow & 97 & 88 & 94 \\
\hline Macula on & 58 & 76 & 78 \\
\hline Inferotemporal quadrant & 33 & 36 & 44 \\
\hline
\end{tabular}

aSolitary RH-associated detachments displayed significantly less felloweye pathology (Fisher's exact test $P<0.001$ ).

$\mathrm{RH}=$ round hole.

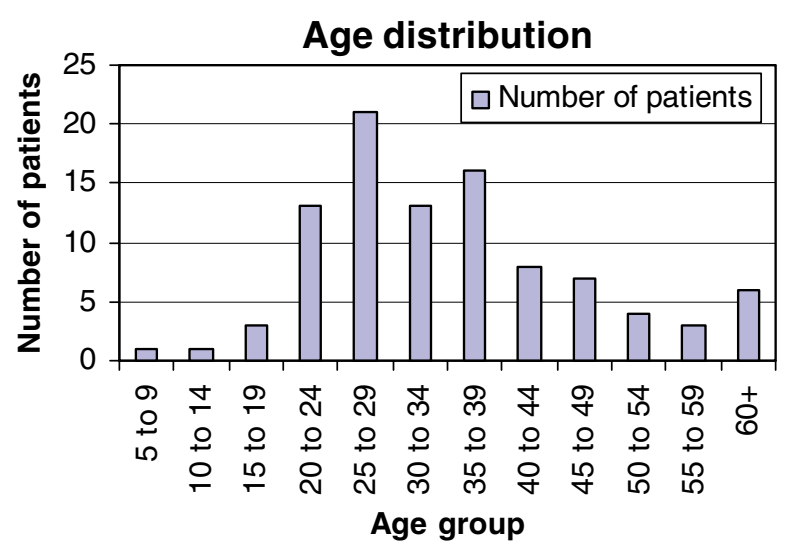

Figure 1 Age distribution of round-hole detachments.

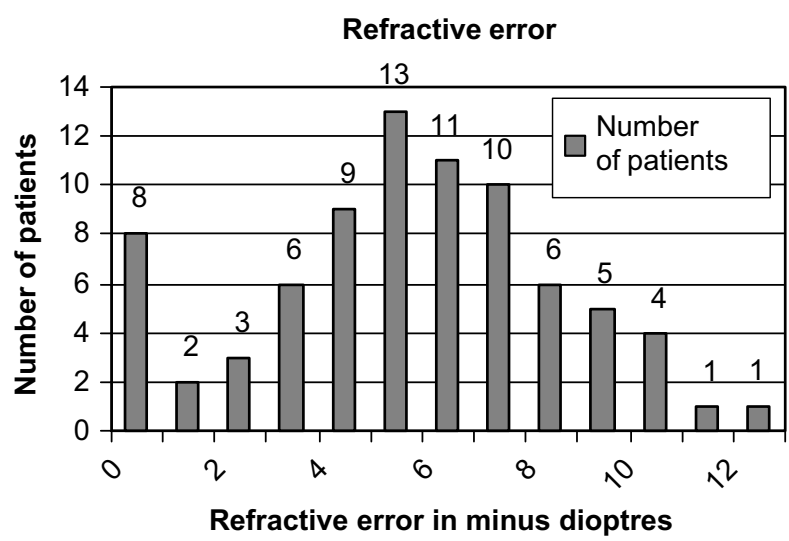

Figure 2 Refractive error in round-hole detachments.

All patients were phakic and there were no associations with preceding trauma.

Blurring of vision was the major presenting symptom, occurring in a total of 60 of $96(63 \%)$ patients; 43 of 60
(72\%) experienced visual blurring alone, and 17 of 60 (28\%) had a combination of blurred vision and flashing lights or floaters. Flashing lights occurred as an isolated symptom in six of 96 patients $(6 \%$ ) while isolated floaters occurred in seven of 96 patients $(7 \%)$. A combination of flashing lights and floaters occurred in six of 96 patients $(6 \%)$. One patient presented with 'visual tremor'. In all, 16 of 96 patients (17\%) were asymptomatic with four patients being erroneously referred as suffering from retinoschisis. Visual acuity at presentation was well preserved in general (Figure 3).

The distribution of the round-hole retinal detachments in reducing order of frequency was as follows: inferotemporal (28\%), superotemporal $21(19 \%)$, temporal $13(12 \%)$, inferior $12(11 \%)$, inferonasal three $(3 \%)$, and superonasal two (2\%). The detachments were predominantly shallow (102 of 110,93\%), with only eight detachments noted to be bullous. All inferotemporal detachments were shallow while five of 21 (23.8\%) superotemporal detachments were bullous. A pigment tidemark suggestive of slow evolution was a feature in 19 of $110(17 \%)$ detachments, of which eight were associated with inferotemporal detachment. Five patients had a localised stable detachment at a second site in the presenting eye.

In 95 of 110 (86\%) detachments, the posterior hyaloid was found to be attached. The status of the vitreous was unrecorded for seven $(6 \%)$ eyes while in eight $(7 \%)$ eyes, a PVD was present. On the basis of associated clinical findings, it was thought that a slowly developing retinal detachment had predated the PVD in these cases. All but one of the patients experiencing photopsia and floaters as presenting feature had an attached posterior hyaloid.

A significant number of round-hole detachments featured similar pathology in the fellow eye. In all, 82 of $96(85 \%)$ patients had round holes in the fellow eye of which 27 (33\%) displayed 'mirror image' position of

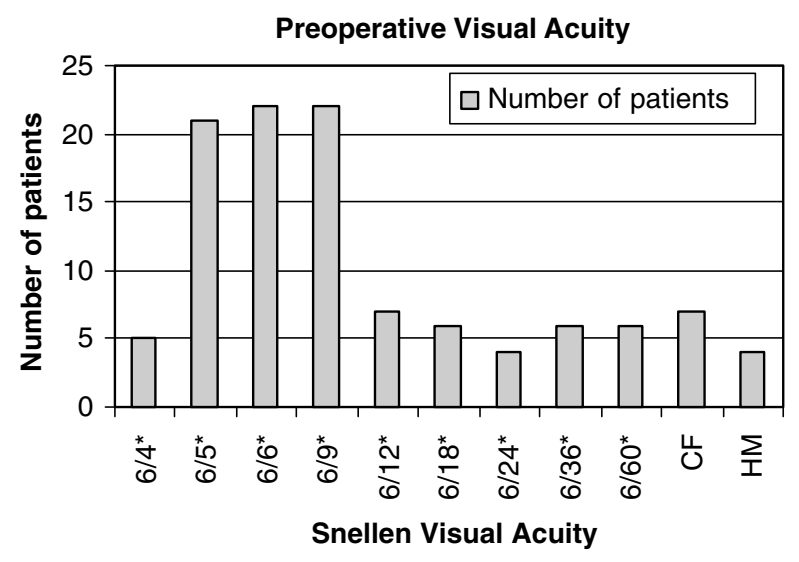

Figure 3 Preoperative visual acuity. 
holes. A subclinical retinal detachment in the fellow eye was present in 17 of $96(18 \%)$ patients.

A total of 100 of 110 (91\%) detachments were repaired with a combination of cryotherapy and scleral buckling procedures. Of these scleral buckle procedures, 14 detachments with multiple round holes were repaired with $2 \mathrm{~mm}$ encircling bands while three detachments with solitary round holes were repaired with $4 \mathrm{~mm}$ radial buckles. In all, 97 other detachments (solitary and multiple round holes) were repaired with circumferential buckles (3-4 mm). Nine (8\%) detachments were treated with retinopexy alone (eight cryotherapy and one argon laser retinopexy). One chronic detachment was managed conservatively. Reattachment of the retina with one operation was achieved in 99 of the 100 (99\%) detachments repaired by buckling. None of the detachments treated by retinopexy alone progressed at the final follow-up. The mean duration of follow-up was 2 years (range 6 months -4 years).

Five patients had postoperative complications. Two patients were steroid responders with raised intraocular pressures, which settled without any sequelae when the postoperative steroid drops were tapered off. Two other patients experienced complications from the scleral buckle. One of them with a history of exotropia secondary to retinopathy of prematurity, experienced an exacerbation of the exotropia. The other patient complained of discomfort from the buckle. Both their symptoms improved with removal of the buckle. The fifth patient had a suture related conjunctival inflammation that settled with removal of the suture.

Final postoperative VA was known in 104 eyes. A VA of $6 / 12$ or better was achieved in 96 of $104(93 \%)$ eyes while 42 eyes (40\%) achieved $6 / 6$ or better (Figure 4 ).

Comparing the characteristics among the subgroups of round hole detachments using the Fisher's exact test, we found that fellow eye pathology in patients with solitary

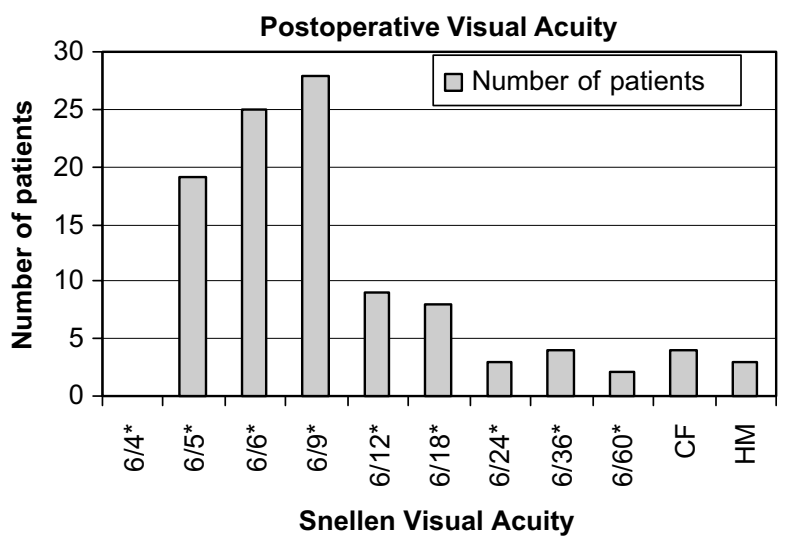

Figure 4 Postoperative visual acuity. round holes was significantly less than patients with multiple round holes $(P<0.001)$.

\section{Discussion}

To our knowledge, this represents the largest published series of round-hole associated retinal detachments. In several autopsy series, retinal round holes in association with lattice have been found to occur in $2.4-18.2 \%$ of eyes. ${ }^{7,8}$ Retinal round holes increase in prevalence with age and occur predominantly in the inferotemporal quadrants. ${ }^{1,9}$ Frequently, the holes are surrounded by a limited amount of subretinal fluid in a cuff-like distribution. ${ }^{10}$ Progression into retinal detachment was initially believed to be infrequent. In a series reported by Davis, ${ }^{2}$ the incidence of subclinical retinal detachment in association with round hole in lattice was $1.5 \%$. In an 18 year study of asymptomatic retinal breaks by Byer, ${ }^{4}$ none of the round hole associated with lattice progressed into clinical detachment.

However, a large survey of primary retinal detachments by Tillery and Lucier ${ }^{4}$ in 1976 showed that $2.8 \%$ of detachments were caused by round holes associated with lattice retinopathy, and in a subsequent study by Morse and Scheie, ${ }^{5} 13.9 \%$ of primary detachments were secondary to round holes. In Japan, the frequency of round-hole detachments was found to be as high as $21 \%$, possibly reflecting the greater prevalence of myopia in this population. ${ }^{6}$

Our study examined detachments secondary to round holes that were lattice round holes and nonlattice round holes. We found that many characteristics were shared across the different subgroups of round-hole detachments. The characteristics of the detachments in our study are in agreement with the findings of Tillery and Lucier, ${ }^{4}$ who reported that $50 \%$ of patients were under the age of 30,60\% were myopic (between -4.0 and -8.0 dioptres), and $43 \%$ of detachments were localised to the inferotemporal quadrant. The status of the vitreous gel however was not reported in the study. In the Japanese study, the vitreous was found to be detached in $34.1 \%$ of patients. ${ }^{6}$ However, the method of diagnosing PVD in their study was not described.

A PVD was present in only $8 \%$ of our patients. The difference probably reflects differences in race and refraction between the patients in the studies. Also in contrast to our findings that showed female preponderance, both the above mentioned studies showed male preponderance. ${ }^{4,6}$ In our study, PVD was diagnosed by the presence of the posterior hyaloid membrane. The presence of a Weiss ring was felt to be an unreliable indicator of a PVD as it could be disrupted during vitreous separation from the retina. However, 
detection of the posterior hyaloid membrane is operator dependent and may be compromised by media clarity.

All subjects in our study were phakic and without association with trauma.

Bilateral pathology was found to be frequent in patients with round-hole detachments. Therefore, examination of the fellow eye is mandatory. Interestingly fellow eye pathology is significantly more frequent in detachments associated with multiple holes as compared to solitary holes. Otherwise the characteristics and behaviour of the detachments in our study did not differ significantly between multiple and solitary round holes, including shallow detachments, slow progression (as characterised by a pigmented line), and high surgical success rates with excellent visual prognosis.

As with any retrospective study this study is not without its weaknesses, especially with regard to the accuracy of the data in the notes. However, most preoperative and operative case note entries had been verified by the vitreoretinal surgeons in charge, thereby minimising error in data accuracy.

In conclusion, round-hole detachments constitute a significant subgroup of retinal detachment with characteristic features. In this series round-hole retinal detachments are characterised as slow-evolving detachments in young females with moderate myopia and attached vitreous. Significant fellow eye pathology is a common feature, with many exhibiting a 'mirror-image' distribution of holes. An excellent prognosis can be achieved with scleral buckle repair avoiding the risks of accelerated nuclear cataract and entry site problems associated with vitrectomy.

\section{References}

1 Byer NE. Prognosis of asymptomatic retinal breaks. Arch Opthalmol 1974; 92: 208-210.

2 Davis MD. Natural history of asymptomatic retinal breaks. Opthalmology 1982; 89: 1033-1039.
3 Byer NE. The natural history asymptomatic retinal breaks. Opthalmology 1982; 89: 1033-1039.

4 Tillery WV, Lucier AC. Round atrophic holes in lattice degeneration - an important cause of phakic retinal detachment. Trans Am Acad Opthalmol Otolaryngol 1976; 81: 509-518.

5 Morse PH, Scheie HG. Prophylactic cryoretinopexy of retinal breaks. Arch Ophthalmol 1974; 92: 204-207.

6 Murakami-Nagasako F, Ohba N. Phakic retinal detachment associated with atrophic hole of lattice degeneration of the retina. Graefe's Arch Clin Exp Ophthalmol 1983; 220: 175-178.

7 Foos RY. Retinal holes. Am J Ophthalmol 1978; 86: 354-358.

8 Straatsma BR, Zeegen PD, Foos RY, Fenman SS. Lattice degeneration of the retina. Trans Am Acad Opthalmol Otolaryngol 1976; 78: 87-113.

9 Byer NE. Clinical study of degeneration of the retina. Trans Am Acad Opthalmol Otolaryngol 1965; 69: 1064-1077.

10 Byer NE. Lattice degeneration of retina. Surv Ophthalmol 1979; 23: 213-248.

11 Ross WH. Retinal dialysis: lack of evidence for a genetic cause. Can J Ophthalmol 1991; 26(6): 309-312.

12 Freeman HM. Fellow eyes of giant retinal breaks. Trans Am Ophthalmol Soc 1978; 76: 343-382.

13 Kanski JJ. Giant retinal tears. Am J Ophthalmol 1975; 79(5): 846-852.

14 Thompson JA, Snead MP, Billington BM, Barrie T, Thopmson JR, Sparrow JM. National audit of the outcome of primary surgery for rhegmatogenous retinal detachment I. Sample and methods. Eye 2002; 16(6): 766-770.

15 Margehria RR, Schepens CL. Macular breaks 1. Diagnosis, etiology and observations. Am J Ophthalmol 1972; 74(2): 219-232.

16 Morita H, Ideta H, Yonemoto J, Sasaki K, Tanaka S Causative factors of retinal detachment in macular holes. Retina 1991; 11: 281-282.

17 Shea M, Schepens CL, Von Pirquet SR. Retinoschisis I. Senile type: a clinical report of one hundred seven cases. Arch Ophthalmol 1960; 63: 1-9.

18 Hagler WS, Woldroff HS. Retinal detachment in relation to senile retinoschisis. Trans Am Acad Ophthalmol Otolaryngol 1973; 77(2): 99-113.

19 Verdaguer J. Juvenile retinal detachment. Pan American Association of Ophhalmology and American Journal of Ophthalmology Lecture. Am J Ophthalmol 1982; 93(2): 145-156. 